\title{
Avaliação de severidade de mancha preta (Cercosporidium personatum) em genótipos de amendoim
}

Submetido - 18 jul. 2021

Aprovado - 31 jul. 2021

Publicado - 30 set. 2021

http://dx.doi.org/10.52755/sas.v.2i(edesp1)145

\begin{abstract}
Natã fernandes Bonatto Pantolfi (iD
Agrícola Bonatto Pantolfi, lacri, SP. E-mail: pantolfibonatto@gmail.com.

André Samir Uchelli iD

Casul Peanuts - Cooperativa Agropecuária de Parapuã, Parapuã, SP. E-mail: samir@casul.com.br.

Programa de Melhoramento do Amendoim - Embrapa, Santo Antônio de Goiás, GO. E-mail: jair.heuert@embrapa.br.
\end{abstract}

Maxuel Fellipe Nunes Xavier (iD Discente de Agronomia do IFMT Campus São Vicente - Centro de Referência de Campo Verde, Campo Verde, MT. E-mail: maxuelfellipe90@gmail.com.

Renan Paio (iD

Casul Peanuts - Cooperativa Agropecuária de Parapuã, Parapuã, SP E-mail: renan.paio@casul.com.br.

Taís de Moraes Falleiro Suassuna (D) Programa de Melhoramento do Amendoim - Embrapa, Santo Antônio de Goiás, GO. E-mail: tais.suassuna@embrapa.br.

\section{RESUMO}

O presente trabalho teve como objetivo avaliar a severidade de mancha preta em diferentes genótipos de amendoim. O experimento foi conduzido na área agrícola de um cooperado da Cooperativa Casul, localizada na região Oeste do estado, no município de lacri-SP, no ano agrícola 2020/21, sendo implantado no dia 16 de dezembro de 2020, propositalmente uma semana posterior a data de plantio da lavoura comercial, cujo objetivo é incentivar a migração de pragas e doenças das lavouras de amendoim com estádios fenológicos mais avançado para os iniciais. $O$ delineamento experimental utilizado foi em blocos casualizados, com quatro repetições. Os tratamentos foram vinte genótipos, sendo dezessete linhagens: 1253 OL, 1876 OL, 19-2673, 2010 OL, 2055 OL, 2101 OL, 2110 OL, 2133 OL, 2250 OL, 2914 OL, 2994 OL, 3088 OL, 3226 OL, 3259 OL, 3308 OL, 3309 OL e 3311 OL, uma cultivar: BRS 423 OL, (desenvolvida pelo PMA da EMBRAPA), uma cultivar BRS 151 L7 (desenvolvida pela EMBRAPA Algodão) e a Granoleico (Argentina produzida pela El Carmen). As parcelas eram constituídas por duas linhas de quatro metros de comprimento, com espaçamento de 0,90 $\mathrm{m}$ e área útil para avaliação de $7,2 \mathrm{~m}^{2}$ por parcela. Com base no presente estudo de campo, conclui-se que os genótipos apresentaram diferença significativa perante a severidade de mancha preta. Os genótipos 2673 OL e 3088 OL apresentaram possíveis genes de resistência ao patógeno e tornando-se promissor para ser utilizado em novas hibridações com intuito de obter um cultivar resistente e/ou tolerante a severidade de mancha preta.

Palavras-chave: Arachis hypogaea L.; Programa de Melhoramento; Produtividade.

\section{Black spot (Cercosporidium personatum) severity assessment in peanut genotypes}

\section{ABSTRACT}

Este é um trabalho de acesso aberto e distribuído sob os Termos da Creative Commons Attribution Attribution-NonCommercial-ShareAlike 4.0 International. 
The present work aimed to evaluate the black spot severity in different peanut genotypes. The experiment was conducted in the agricultural area of a cooperative member of the Casul Cooperative, located in the western region of the state, in the municipality of lacri-SP, in the agricultural year 2020/21, being implemented on December 16, 2020, purposely a week after date of planting of the commercial crop, whose objective is to encourage the migration of pests and diseases from peanut crops with phenological stages more advanced to the initial ones. The experimental design used was in randomized blocks, with four replications. The treatments were twenty genotypes, with seventeen strains: 1253 OL, 1876 OL, 19-2673, 2010 OL, 2055 OL, 2101 OL, 2110 OL, 2133 OL, 2250 OL, 2914 OL, 2994 OL, 3088 OL, 3226 OL, 3259 OL, 3308 OL, 3309 OL and 3311 OL, a cultivar: BRS 423 OL, (developed by the EMBRAPA PMA), a cultivar BRS 151 L7 (developed by EMBRAPA Algodão) and Granoleico (Argentina produced by El Carmen). The plots were constituted by two lines of four meters in length, with spacing of 0.90 $m$ and useful area for evaluation of $7.2 \mathrm{~m}^{2}$ per plot. Based on the present field study, it is concluded that the genotypes showed a significant difference regarding the severity of black spot. The 2673 OL and 3088 OL genotypes showed possible resistance genes to the pathogen and are promising to be used in new hybridizations in order to obtain a cultivar resistant and/or tolerant to black spot severity.

Keywords: Arachis hypogaea L..; Improvement Program; Productivity.

\section{Evaluación de la gravedad de la mancha negra (Cercosporidium personatum) en genotipos de maní}

\section{RESUMEN}

El presente trabajo tuvo como objetivo evaluar la severidad de la mancha negra en diferentes genotipos de maní. El experimento se realizó en el área agrícola de una cooperativa miembro de la Cooperativa Casul, ubicada en la región occidental del estado, en el municipio de lacri-SP, en el año agrícola 2020/21, siendo implementado el 16 de diciembre. 2020, intencionalmente una semana después de la fecha de siembra del cultivo comercial, cuyo objetivo es incentivar la migración de plagas y enfermedades de los cultivos de maní con estadios fenológicos más avanzados a los iniciales. El diseño experimental utilizado fue en bloques al azar, con cuatro repeticiones. Los tratamientos fueron veinte genotipos, con diecisiete cepas: $1253 \mathrm{OL}, 1876 \mathrm{OL}$, 19-2673, 2010 OL, 2055 OL, 2101 OL, 2110 OL, 2133 OL, 2250 OL, 2914 OL, 2994 OL, 3088 OL, 3226 OL, 3259 OL, 3308 OL, 3309 OL y 3311 OL, un cultivar: BRS 423 OL, (desarrollado por la EMBRAPA PMA), un cultivar BRS 151 L7 (desarrollado por Embrapa Algodão) y Granoleico (Argentina producido por El Carmen). Las parcelas constaron de dos líneas de cuatro metros de longitud, con un espaciamiento de 0.90 my una superficie útil para evaluación de $7.2 \mathrm{~m}^{2}$ por parcela. Con base en el presente estudio de campo, se concluye que los genotipos mostraron una diferencia significativa en cuanto a la severidad de la mancha negra. Los genotipos 2673 OL y 3088 OL mostraron posibles genes de resistencia al patógeno y prometen ser utilizados en nuevas hibridaciones para obtener un cultivar resistente y/o tolerante a la severidad de la mancha negra.

Palabras clave: Arachis hypogaea L.; Programa de Mejoramiento; Productividad.

\section{Introdução}

A pinta preta ou mancha preta (Cercosporidium personatum) é uma das principais doenças na cultura do amendoim (Arachis hypogaea). As condições climáticas favoráveis, como temperatura média acima de $20{ }^{\circ} \mathrm{C}$, umidade relativa igual ou superior a 90\%, consistem em um ambiente propício para o desenvolvimento e ocorrência de doenças, principalmente a 
C. personatum (BARRETO, 2016; MARCH et al., 1993). Os sintomas caracterizam-se por lesões circulares (1 a $7 \mathrm{~mm}$ ) de diâmetro, de cor marrom escura na parte adaxial do limbo foliar e na abaxial apresenta coloração preta, com possibilidade ou não de ser circundada por um pequeno halo (BARRETO, 1997).

Os esporos ou conídios produzidos nas folhas são anfígenos, porém concentram-se principalmente na parte abaxial, podendo-se apresentar na forma de círculos concêntricos nas lesões. Com isso, as folhas começam a apresentar uma coloração escura, influenciando numa possível redução fotossintética, oriundo mecanismo de defesa da planta por meio da prematura e intensa queda das folhas (GERLAGH; BOKDAM, 1973; MORAES; GODOY, 1997). Estes sintomas da $C$. personatum geralmente são constatados no final do ciclo da cultura, na fase de enchimento dos grãos, podendo causar redução da área foliar e consequente redução da produtividade (RIBEIRO et al., 2018).

Estudos de Ribeiro et al. (2019), testando diferentes estratégias de controle deste patógeno, constatou uma redução na produtividade de vagens de $48,7 \%$, comparando a testemunha que não recebeu nenhum controle. Corroborando com Suassuna et al. (2009), que menciona perdas de produtividade estimadas em torno de $50 \%$ quando comparado ao controle (testemunha). Por outro lado, a cultura está exigindo mais de 8 aplicações preventivas de defensivos agrícolas acarretando uma elevação de custos, seja pelo produto e pela operação agrícola do trânsito das máquinas agrícolas nas lavouras comerciais (RIBEIRO et al., 2018).

Embora haja disponibilidade de acessos de amendoim resistentes e suscetíveis a $C$. personatum, a dificuldade no melhoramento genético ocorre por motivo em que a resistência é geralmente determinada por herança quantitativa e o amendoim possui suscetibilidade a várias outras doenças importantes (MORAES; GODOY, 1997). Vale ressaltar que espécies silvestres possuem um verdadeiro reservatório de genes úteis, com possibilidade de serem transferidos para as espécies cultivadas, mas há limitações nessa hibridação: como a esterilidade e inviabilidade dos híbridos 
e suas progênies, e a incompatibilidade entre espécies (PRESTES; GOULART, 1995). Porém, nos últimos anos com o aperfeiçoamento das técnicas do melhoramento genético, houve a possibilidade da introgressão de genes desejáveis de resistência, oriundos de espécies silvestres para uso nos programas de melhoramento para desenvolvimento de novas cultivares (GAO et al., 2021)

É fundamental para o melhoramento genético desenvolver cultivares resistentes ou com tolerância, oriundas de espécies silvestres. Muitos materiais/linhagens resultam em bons resultados de tolerância a doenças, porém apresentam características agronômicas indesejáveis, como arquitetura da planta, padrão de vagens e sementes e baixa produtividade. Com base nisso, uma série de cruzamentos do material resistente, com cultivares de Programa de Melhoramento são fundamentais, com objetivo de recuperar as caraterísticas agronômicas favoráveis (MICHELOTTO et al., 2013). Maiores níveis de resistência às cercosporioses foram obtidos nas fontes silvestres $A$. magna, $A$. batizocoi, $A$. stenosperma e $A$. cardenassi (MICHELOTTO et al., 2015).

Os avanços são significativos sendo que Suassuna et al. (2020) identificou o genótipo 18-2673 como sendo um material genético promissor, com nota de 2,94. Outro fator importante a destacar que este trabalho, pois servem para submeter os novos genótipos numa condição de lavoura comercial, para avaliar seu desempenho agronômico. O presente trabalho teve como objetivo avaliar a severidade de mancha preta em diferentes genótipos de amendoim.

\section{Material e métodos}

O experimento foi conduzido na área agrícola da família Bonatto Pantolfi, cooperado da Cooperativa Casul, localizada na região oeste do estado, no município de lacri-SP, no ano agrícola 2020/21. Foi implantado no dia 16 de dezembro de 2020, propositalmente uma semana posterior a data de plantio da lavoura comercial, cujo objetivo é incentivar a migração de pragas e doenças das lavouras de amendoim com estádios fenológicos mais 
avançados para os iniciais. Uma época fora da janela ideal de semeadura, sendo que as chuvas atrasaram nesta safra, segundo a CONAB (2021).

O delineamento experimental utilizado foi em blocos casualizados, com quatro repetições. Os tratamentos foram vinte genótipos, sendo dezessete linhagens: 1253 OL, 1876 OL, 19-2673, 2010 OL, 2055 OL, 2101 OL, 2110 OL, 2133 OL, 2250 OL, 2914 OL, 2994 OL, 3088 OL, 3226 OL, 3259 OL, 3308 OL, 3309 OL e 3311 OL, uma cultivar: BRS 423 OL, (ambas desenvolvidas pelo PMA da EMBRAPA), uma cultivar BRS 151 L7 (desenvolvida pela Embrapa Algodão) e a Granoleico (Argentina produzida pela El Carmen). As parcelas eram constituídas por duas linhas de 4 metros de comprimento, com espaçamento de $0,90 \mathrm{~m}$ e área útil para avaliação de $7,2 \mathrm{~m}^{2}$ por parcela.

O manejo de correção da fertilidade do solo foi realizado de acordo com as necessidades observadas por meio da análise de solo e o manejo fitossanitário realizado conforme as recomendações para a cultura, pelos agrônomos da Cooperativa. $O$ estande médio de plantas foi de 20 plantas.m1. Após 112 dias após o plantio (DAP), foi realizada avaliação de severidade de mancha preta (Cercosporidium personatum), usando uma escala diagramática da incidência com notas de 1 a 9 , em que 1 indicava a planta sem doença e 9 desfolha intensa (SUBRAHMANYAM et al., 1982).

Os dados foram submetidos à análise de variância pelo Teste $\mathrm{F}$ e as médias dos tratamentos foram comparados pelo teste de Scott-Knott, no nível de $p \geq 0,05$ de probabilidade, por meio do programa computacional SISVAR 5.6 (FERREIRA, 2019).

\section{Resultados e discussão}

Houve diferença significativa para as notas de severidade de mancha preta em função dos diferentes genótipos de amendoim. Observase baixa severidade com o genótipo 3088 OL $(1,3)$, seguido do 2673 OL $(2,4)$ (Tabela 1 e Figura 1). Resultados estes obtidos são extremamente satisfatórios e promissores para demais avaliações agronômicas destas 
linhagens, visando o registro de possíveis cultivares resistentes a alta incidência de $C$. personatum na lavoura.

Tabela 1. Notas de severidade de mancha preta em função de diferentes genótipos de amendoim. lacri-SP, 2020/21.

\begin{tabular}{|c|c|c|c|}
\hline \multirow{2}{*}{ Genótipos } & Nota de Severidade & \multirow{2}{*}{ Genótipos } & Nota de Severidade \\
\hline & $(1-9)$ & & $(1-9)$ \\
\hline $3088 \mathrm{OL}$ & $1,3 \mathrm{a}$ & $3259 \mathrm{OL}$ & $7,6 \mathrm{~d}$ \\
\hline $2673 \mathrm{OL}$ & $2,4 \mathrm{~b}$ & 2914 OL & $7,6 \mathrm{~d}$ \\
\hline $3309 \mathrm{OL}$ & $7,0 \mathrm{c}$ & $1253 \mathrm{OL}$ & $8,1 \mathrm{e}$ \\
\hline 3226 OL & $7,2 \mathrm{c}$ & $1876 \mathrm{OL}$ & $8,1 \mathrm{e}$ \\
\hline BRS $423 \mathrm{OL}$ & $7,3 \mathrm{c}$ & Granoleico & $8,3 \mathrm{e}$ \\
\hline $3311 \mathrm{OL}$ & $7,3 \mathrm{c}$ & $2110 \mathrm{OL}$ & $8,5 f$ \\
\hline 2994 OL & $7,4 d$ & $2250 \mathrm{OL}$ & $8,6 \mathrm{f}$ \\
\hline $2133 \mathrm{OL}$ & $7,5 \mathrm{~d}$ & $2055 \mathrm{OL}$ & $8,6 \mathrm{f}$ \\
\hline $3308 \mathrm{OL}$ & $7,5 \mathrm{~d}$ & $2101 \mathrm{OL}$ & $8,7 f$ \\
\hline $2010 \mathrm{OL}$ & $7,6 \mathrm{~d}$ & BRS 151 L7 & $8,8 \mathrm{f}$ \\
\hline Média Geral & & 7,2 & \\
\hline C.V. (\%) & & 2,4 & \\
\hline $\mathrm{Pr}>\mathrm{FC}$ & & $>0,0001^{*}$ & \\
\hline
\end{tabular}

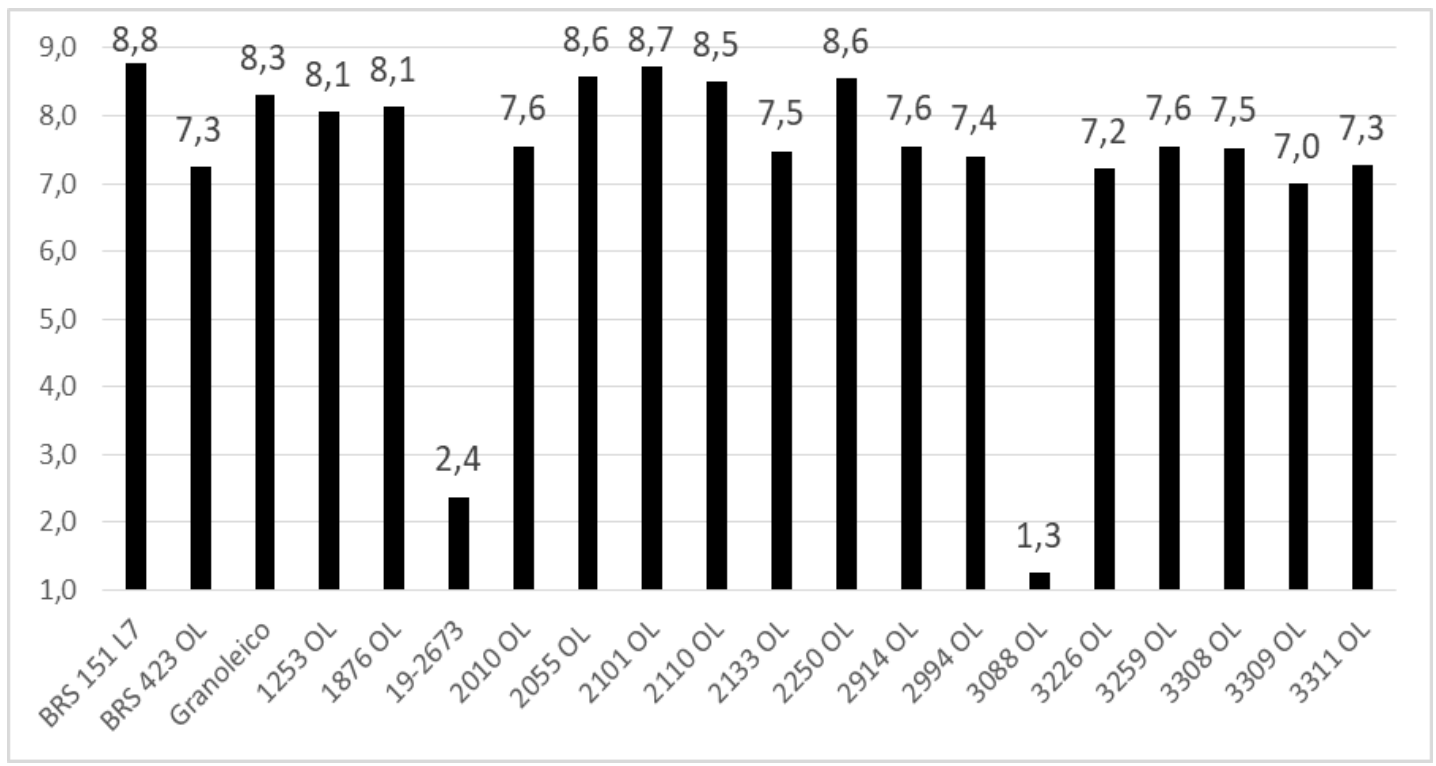

Figura 1. Notas de severidade de mancha preta em função de diferentes genótipos de amendoim. lacri-SP, 2020/21.

Verificou-se que as folhas apresentaram muitas lesões, sendo menos severas no ápice, precedido de desfolha intensa na parte intermediária e completa na parte inferior da plana (SUBRAHMANYAM et al., 
1982) nos genótipos 2914 OL (7,6), 3259 OL (7,6), 2010 OL (7,6), 3308 OL $(7,5), 2133$ OL $(7,5)$ e 2994 OL $(7,4)$, seguidos do 3311 OL $(7,3)$, BRS 423 OL $(7,3), 3226$ OL $(7,2)$ e 3309 OL $(7,0)$ (Tabela 1 e Figura 1$)$.

Com isso, restam-se o BRS $151 \mathrm{~L} 7(8,8), 2101 \mathrm{OL}(8,7), 2055 \mathrm{OL}$ $(8,6), 2250 \mathrm{OL}(8,6)$ e $2110 \mathrm{OL}(8,5)$, seguidos do Granoleico $(8,3), 1876 \mathrm{OL}$ $(8,1)$ e 1253 OL $(8,1)$ (Tabela 1 e Figura 1). Estes genótipos apresentaram desfolha na parte inferior e intermediária, com lesões severas e alguma desfolha no ápice (SUBRAHMANYAM et al., 1982).

\section{Conclusões}

Com base no presente estudo de campo, conclui-se que os genótipos apresentaram diferença significativa perante a severidade de mancha preta. Os genótipos 2673 OL e 3088 OL apresentaram possíveis genes de resistência ao patógeno e tornando-se promissor para ser utilizado em novas hibridações com intuito de obter um cultivar resistente e/ou tolerante a severidade de mancha preta.

\section{Agradecimentos}

Os autores agradecem à família Bonatto Pantolfi pela condução da área experimental em sua área agrícola, à CASUL - Cooperativa Agropecuária de Parapuã-SP, pelo suporte financeiro. Este trabalho também está vinculado ao Programa de Melhoramento do Amendoim da Embrapa (SEG 20.18.01.021.00). 


\section{Referências}

BARRETO, M. Doenças do amendoim (Arachis hypogaea L.). In: KIMATI, H.; AMORIM, L.; BERGAMIN FILHO, A.; CAMARGO, L. E. A.; REZENDE, J. A. M. Manual de Fitopatologia: Doenças de Plantas Cultivadas, 3. ed., São Paulo: Ceres, 1997. p. 65-77.

BARRETO, M. Doenças do Amendoim. In: AMORIM, L. et al. (Ed.). Manual de Fitopatologia: Volume 2 - Doenças das Plantas Cultivadas. $5^{\mathrm{a}}$ ed. Ouro Fino: Ceres, 2016. p. 75-81.

GAO, D. et al. ValSten: uma nova espécie selvagem derivada de alotetraplóide para aumentar a diversidade genética da cultura do amendoim (Arachis hypogaea L.). Genet. Resour. Crop. Evol., v. 68, n. 1, p. 14711485, 2021.

GERLAGH, M.; BOKDAM, M. La production de l'arachide en fonction de la réduction de la photosynthèse par la cercosporiose ou ses simulations. Oléagineux, v.28, n.7, p.347-350, 1973.

$\mathrm{MARCH}, \mathrm{G}$. J. et al. Efecto de las temperaturas, humedad relativa y precipitaciones sobre el desarrollo de la viruela, causada por Cercospora arachidicola Hori y Cercosporidium personatum (Berk. \& Curt.) (Deighton) en maní (Arachis hypogea L.) Bol. San. Veg. Plagas, v. 19, p. 227-235, 1993.

MICHELOTTO, M. D.; GODOY, I. J., FÁVERO, A. P. Espécies silvestres como fontes de resistência a pragas e doenças do amendoim. Pesquisa \& Tecnologia, v. 10, n. 2, p. 1-7, 2013.

MICHELOTTO, M. D. et al. Identification of fungus resistant wild accessions and interspecific hybrids of the genus Arachis. PLoS ONE, v. 10, n. 6, p. e0128811, 2015.

MORAES, S. A.; GODOY, I. J. Amendoim (Arachis hypogaea L.) - Controle de doenças. In: VALE, F. X. R.; ZAMBOLIM, L. Controle de Doenças de Plantas: grandes culturas, Viçosa: UFV, 1997. p.1-49.

PRESTES, A. M.; GOULART, L. R. Transferência de resistência a doenças de espécies silvestres para espécies cultivadas. Revisão Anual de Patologia de Plantas, v. 3, p. 315-363, 1995.

SUASSUNA N. D. Doenças. In: SANTOS, R. C.; FREIRE, R. M. M.; SUASSUNA, T. M. F. Amendoim: o produtor pergunta, a Embrapa responde. Brasília: Embrapa, 2009. p. 66-68.

SUASSUNA, T. M. F. et al. Uso de espécies silvestres como fontes de resistências às cercosporioses no amendoim. South American Sciences, v. 1, n. 2, p. e2025, 2020.

SUBRAHMANYAM, P. et al. Resistance to rust and late leaf spot diseases in some genotypes of Arachis hypogaea. Peanut Science, v. 9, p. 9-14, 1982. 
RIBEIRO, R. P.; HEUERT, J. Controle da mancha preta do amendoim utilizando diferentes formulações de clorotalonil associadas com triazóis e estrobirulina. In: Encontro Sobre a Cultura do Amendoim, 15., 2018, Jaboticabal. Anais eletrônicos... Campinas: GALOÁ, 2018.

RIBEIRO, R. P.; HEUERT, J. Controle de mancha preta do amendoim utilizando diferentes estratégias. In: Encontro Sobre a Cultura do Amendoim, 16., 2019, Jaboticabal. Anais eletrônicos... Campinas: GALOÁ, 2019. 